\title{
O sujeito em movimento: pós-moderno, migrante e transnacional
}

\author{
The subject in motion: postmodern, migrant and transnational 1
}

Janet M. Paterson

University of Toronto - Toronto - Ontario - Canadá

$\diamond$

\begin{abstract}
Resumo: A literatura contemporânea é caracterizada por uma variedade de representações da identidade pessoal. Desde os anos 1960, a presença do sujeito narrativo no discurso literário é ubíqua. Neste artigo, discuto três modelos subjacentes à representação dos personagens ficcionais na ficção do Quebec: pós-modernismo, literatura imigrante e cultura transnacional. O princípio norteador da análise é que o sujeito literário é fortemente condicionado por mudanças sociológicas e epistemológicas. Dizer "Eu" na literatura contemporânea é expressar a multiplicidade do sujeito pós-moderno, a angústia da voz imigrante e a emancipação do personagem ficcional transnacional.
\end{abstract}

Palavras-chave: Pós-Modernismo; Literatura imigrante; Literatura transnacional; Literatura do Quebec; Ficção contemporânea

\begin{abstract}
Contemporary literature is characterized by the variety of representations of personal identity. Since the 1960 's, the presence of the narrative subject in literary discourse is ubiquitous. In my article, I discuss three models that underlie the representation of fictional characters in Quebec fiction: postmodernism, immigrant literature and transnational literature. The principle guiding my analysis is that the literary subject is strongly determined by sociological and epistemological changes. To say "I" in contemporary literature is to express the multiplicity of the postmodern subject, the angst of the immigrant voice and the emancipation of the transnational fictional character.
\end{abstract}

Keywords: Postmodernism; Immigrant literature; Transnational literature; Quebec literature; Contemporary fiction

Não se pode negar mais a complexidade da construção identitária na literatura contemporânea. Desde os anos 1960 , o sujeito se inscreve cada vez mais vigorosamente, ao que parece, no discurso fictício. Além disso, as metamorfoses do sujeito são numerosas e submetidas a múltiplas análises. Constroem-se, descontroem-se e reconstroem-se sujeitos femininos, lésbicos, gays, imigrantes, sofredores, minoritários, majoritários, etc. Este volume aborda, entre outros, os temas do sujeito exilado, feminino, mítico, autobiográfico, intertextual, acadiano e moribundo. Quantos sujeitos! Suas metamorfoses são de fato numerosas.

Poderíamos, evidentemente, questionar a representação massiva e variada do sujeito na literatura contemporânea. A resposta a esse questionamento é, com certeza, muito complexa e remete em parte, como propõe Charles Taylor, ao período romântico, que deu uma grande importância à expressão individual. Porém, além do período romântico, eu estabeleceria como fio condutor de minha análise as várias mudanças socioculturais e epistemológicas que influenciaram a representação do sujeito na literatura. Nesse contexto, vou discutir três grandes eixos que sustentam a representação de numerosos sujeitos fictícios: o pós-modernismo, os movimentos de migração e o pensamento transnacional. Embora a abordagem desses fenômenos não seja exaustiva (não trato, por exemplo, da questão do sujeito autobiográfico ou autofictício, que deu tanto o que falar nos últimos anos, ou do sujeito pós-colonial ${ }^{2}$ ), certamente esses três

\footnotetext{
1 Tradução de Patrícia C.R. Reuillard (UFRGS).

2 A autoficção e o pós-colonialismo ultrapassam o âmbito de minha análise. Por outro lado, meu objetivo é, em parte, demonstrar os vínculos existentes entre, em certos casos, o pós-modernismo, a literatura migrante e o pensamento transnacional.
} 
eixos têm forte impacto na representação literária do sujeito e da questão identitária. Dizer "eu" na literatura contemporânea equivale, frequentemente, a expressar a difração de um sujeito pós-moderno, o desatino de um sujeito migrante e a libertação de um sujeito transnacional.

Falar do sujeito ou da identidade narrativa não é evidente. Isso significa que se deve estabelecer uma axiologia para delimitar conceitualmente a construção do sujeito. Existem muitas ferramentas e teorias que, tais como as teorias da enunciação, nos auxiliam a delinear a questão do sujeito. Quanto a mim, inspiro-me nos textos de Éric Landowski e estabeleço o princípio básico de que os procedimentos de espacialização e de temporalização determinam, em grande parte, a construção identitária.

Semioticamente falando, isso já está claro, não há espaço-tempo como referente puro ou como objeto de estudo dado a priori. Existem apenas sujeitos que, através das modalidades variáveis da apreensão de seu 'aqui-agora', constroem as condições de sua relação consigo mesmos, como 'eu'. Desse ponto de vista, toda construção identitária, toda "busca de si mesmo" passa por um processo de localização do mundo. (LANDOWSKI, 1997, grifo do autor)

Se, como afirma Landwoski, toda construção identitária passa efetivamente por um processo de localização do mundo, a apreensão do espaço e do tempo é uma operação que envolve o regime identitário do sujeito e permite sua construção, reconstrução e transformação.

Em um plano mais geral, deve-se também dar conta das epistemes que subentendem a representação de diferentes sujeitos. O que anima o espírito pós-moderno, a escritura migrante, o pensamento transnacional? Em outras palavras, que pensamento e que vontade influenciam as diferentes posições identitárias?

\section{O sujeito pós-moderno}

O sujeito pós-moderno ainda existe? O pós-modernismo continua sendo uma corrente intelectual influente ou hoje em dia se deveria falar de pós-modernismo? Contrariamente a certas expectativas, o pós-modernismo não está desaparecendo de modo algum, pois ele continua a estruturar um método cognitivo, interpretativo e criativo (encontram-se, por exemplo, traços pós-modernos em certos escritos migrantes e transnacionais). Segundo pesquisas efetuadas na Modern Language Association (MLA), os estudos sobre o pós-modernismo na literatura são cada vez mais numerosos ${ }^{3}$.

Para Jean-François Lyotard, o pós-modernismo representa uma mudança epistemológica e uma transformação cultural importantes que datam dos anos cinquenta. Todos conhecem e sempre repetem, aliás, sua célebre definição: "Simplificando ao extremo, considera-se 'pós-moderno' a incredulidade acerca das metanarrativas" $(1979$, p. 7). Ou seja, o pós-modernismo designa um saber que questiona os grandes discursos filosóficos, históricos e científicos e os sistemas de pensamento baseados nas noções de verdade e de unicidade. Ele traz à tona uma crise de legitimação na qual os grandes discursos perderam seu valor de unificação. Segundo Lyotard, o pós-modernismo é um saber heterogêneo ligado a uma nova legitimação fundada no reconhecimento dos jogos de linguagem: "O saber pós-moderno não é apenas o instrumento dos poderes. Ele refina nossa sensibilidade às diferenças e reforça nossa capacidade de suportar o incomensurável" (p. 8-9).

Quais são os paradigmas identitários relacionados ao pensamento pós-moderno? ${ }^{4}$ Em outras palavras, como se exprime o sujeito pós-moderno no texto literário? No plano da enunciação, ele privilegia o "eu" (rejeitando, assim, toda voz narrativa onisciente) e frequentemente adota a postura de um autor ou autora, de um editor ou editora, de um sujeito que escreve. Muitas vezes, o sujeito é desdobrado, cindido, fragmentado (como em Trou de mémoire, de Hubert Aquin). Na obra La Vie en prose, de Yolande Villemaire, ao contrário, tem-se uma polifonia de vozes femininas que se fazem ouvir de formas individuais e coletivas para expressar sua desconfiança em relação às noções de autoridade ou de visão totalizante. A relação do sujeito pós-moderno com o espaço-tempo também é múltipla e heterogênea: a unidade do espaço é abolida em proveito de espaços múltiplos, e o tempo perde seu aspecto cronológico e unitário. O sujeito pós-moderno mistura alegremente os tempos e os espaços:

Eu eu eu na espiral do tempo perdido na noite dos tempos e entretanto não sou eu que falo, é eu eu eu um outro e eu é entretanto uma outra que rouba uma frase no continuum das caligrafias palimpsésticas do que se chama de coisas da vida por uma espécie de obscurecimento que nos faz esquecer o cenário fictício e toda a profundidade do canto das esferas subatômicas que rolam sob nossas peles de iguanas galápagos em um instante de gênese. (VILLEMAIRE, 1980, p. 238)

Pode-se constar que o heterogêneo é o ponto focal da escritura pós-moderna, que opera a mistura das formas, a impureza dos estilos, a contaminação dos gêneros e a fragmentação dos sujeitos. Muitas vezes lúdico, frequentemente contestatário, sempre inventivo, o sujeito pós-moderno escreve e se escreve em um espírito de júbilo, transformando os discursos, deixando aflorarem

\footnotetext{
3 Por exemplo, segundo pesquisas efetuadas na Modern Language Association International Bibliography, entre 1970-1984, 13 livros foram publicados sobre o tema, ao passo que, entre 1985-1999, foram 141.

4 Ver Janet Paterson, Moments postmodernes dans le roman québécois.
} 
as divergências. Mutável e fértil, o sujeito pós-moderno se insere na literatura de inúmeros países.

\section{O sujeito migrante}

A partir dos anos 1980, ocorre uma mudança importante na representação do sujeito no campo literário francófono (no Canadá, no Quebec e na França) devido ao fenômeno da escritura migrante. Para evitar malentendidos, esclareço que se trata de textos escritos por emigrantes que relatam sua experiência de migração e sua vida no país de acolhida. Hoje em dia, são numerosos os exemplos de textos migrantes: La Québécoite de Régine Robin, A Casa dos Espelhos de Sergio Kokis, Le Figuier enchanté de Marco Micone, Le bonheur a la queue glissante de Abla Farhoud, La Dot de Sara de Marie-Célie Agnant, entre outros.

Essa mudança na literatura é, evidentemente, resultado dos movimentos de migração do final do século XX. Esses textos não apenas renovaram a instituição literária, mas também modificaram a representação do sujeito na escrita, nela inscrevendo a voz de estrangeiros, de exilados, ou seja, de pessoas que se percebem como Outro no país de acolhida. Para analisar o sujeito migrante, pode-se utilizar a noção de entre-lugar, que assinala a representação de um novo espaço identitário, discursivo e social.

O entre-lugar caracteriza, em primeiro lugar, a enunciação, geralmente na primeira pessoa: "Eu sou Outro", "Eu sou estrangeiro - ou estrangeira", "Eu sou exilada", afirmarão não sem pesar muitos sujeitos migrantes. O que se deve ressaltar nessas afirmações é que o sujeito migrante se inscreve no discurso, evidenciando uma identidade que se funda no duplo - "eu sou Outro", na distância - "Eu sou estrangeiro", na perda de posse identitária - "Eu sou exilada". Nesses enunciados, tudo testemunha uma dolorosa clivagem identitária causada pela relação do sujeito com o espaço-tempo. Para dar um exemplo desse funcionamento, vou analisar brevemente a representação do sujeito em $A$ Casa dos Espelhos de Sergio Kokis 5 .

A intriga poderia ser assim resumida: é um relato autobiográfico fictício que coloca em cena um narrador brasileiro que conta suas lembranças de infância e de adolescência no país natal, enquanto relata sua experiência de imigrante em Montreal. Ele se designa abertamente, sem a menor ambiguidade, como um estrangeiro, um exilado na sociedade quebequense que o acolheu: "aquele que tanto buscou partir não se acostuma em seguida à solidão dos grandes espaços [...] a viagem se transformou

\footnotetext{
5 Retomo uma parte de minha análise em Figures de l'Autre dans le roman québécois, com algumas modificações.
}

em exílio" (p. 363). Sua narrativa, em primeira pessoa, alterna geralmente de um capítulo a outro as lembranças de seu passado distante no Brasil e as reflexões sobre sua vida em Montreal.

Apesar dessa alternância, que produz um vaivém contínuo entre o passado e o presente, o Brasil e o Quebec, toda a narrativa está no presente. Tudo se dá como se o passado e o presente pudessem não somente se justapor, mas se confundir no nível temporal do discurso. Esse fenômeno é ainda mais surpreendente porque o narrador, como ele próprio relembra, vive em Montreal há 25 anos.

É evidente, do início ao fim do romance, que o narrador está em uma situação de disjunção total em relação a seu novo meio, prisioneiro de um entre-lugar espacial e identitário. "Enterrado", como ele mesmo diz, no subsolo de um prédio, é um homem solitário, alienado e infeliz, que se compraz em criticar, de maneira ácida, a sociedade de acolhida. Deste modo, não ocorre nenhum transformação com este "desenraizado", "estrangeiro", "deslocado", como ele gosta de se descrever.

Vale ressaltar que, para o sujeito migrante, toda transformação identitária depende de sua relação com o espaço-tempo. Para evidenciar isso, esclareçamos, seguindo Landowski, que o espaço-tempo não existe como uma dimensão exterior ao sujeito. Ao contrário, como o autor destaca, os "procedimentos de espacialização e de temporalização [...] parecem condicionar toda forma de apreensão de nosso ser no mundo enquanto mundo significante" (1997, grifo do autor).

Convém, portanto, interrogar-se sobre a relação do protagonista de A Casa dos Espelhos com o espaço-tempo. Em que medida a apreensão do espaço tem repercussões sobre a construção identitária do protagonista?

Ao evocar o passado, o narrador conta os acontecimentos marcantes de sua infância e de sua adolescência no Brasil, particularmente sua vida familiar, estudantil e social. Sua narrativa nos leva cronologicamente da infância à idade adulta, quando deixa o país.

$\mathrm{O}$ relato do passado do narrador - contado no presente, relembro - possibilita não somente descobrir a vida interior de um jovem brasileiro de outrora, suas alegrias, temores, desejos, mas também o espaço exterior e social no qual ele viveu, isto é, um espaço vivo, vibrante, nas ruas, bares, portos, vilarejos e feiras.

De modo geral, dois topoi marcam a relação do narrador com o espaço brasileiro. Primeiramente, o da deambulação: nas ruas, nos parques, na cidade, nos portos e no país inteiro, através das montanhas e dos vilarejos, durante uma viagem com um grupo de jovens. Assim, a relação do narrador com o espaço é dinâmica e submetida a um movimento contínuo. O segundo tópos se situa no plano sensorial. No relato da vida brasileira, 
as experiências sensoriais do protagonista impregnam a narrativa: odores de peixes ou de incenso, música nas igrejas ou nos bares, toque de pele úmida e sensual, gosto de fruta e de café e, sobretudo, olhares ávidos sobre um mundo multicolor e vibrante. São experiências sensoriais intensas que definem, de certo modo, a relação do jovem com o mundo exterior e envolvem suas capacidades cognitivas. Relação intensa com o aqui-agora da vida brasileira.

Se o romance inteiro fosse unicamente um relato memorial sobre o passado do narrador, não haveria por que se interrogar sobre a noção de mudança no plano identitário. Mas, como se trata de uma narrativa migrante cujo espaço-tempo se situa também em Montreal, a sombra de uma falha e o início de uma inquietude planam sobre os procedimentos de espacialização e de temporalização relativos às descrições da vida brasileira. Sua eficácia e plenitude podem parecer desconcertantes na medida em que, em todo o romance, eles inserem o sujeito em uma relação não com o aqui-agora, que é a de Montreal, na realidade, mas com outro lugar-passado brasileiro, bem distante, como já indiquei. Isso equivalente, portanto, a dizer que o narrador adulto, que vive no Quebec, parece se situar, no plano identitário e existencial, em seu passado. E o que acontece com seu presente?

Nos capítulos que alternam com o passado, o narrador descreve, sempre no presente, a vida em seu país de adoção. Encerrado no subsolo de seu ateliê, visto que é pintor, ele fornece certos detalhes de sua vida cotidiana em Montreal. O que surpreende, nessas descrições, é o imenso contraste com seu relato do passado.

Enquanto a vida no Brasil se caracterizava pelo movimento e pela abertura para o social, o espaço montrealense é de natureza claustral, limitado ao prédio, a algumas incursões em shoppings e a uma referência ao local de trabalho. A dimensão sensorial está quase inteiramente ausente (salvo na descrição dos quadros), e o espaço social se mostra terrivelmente reduzido, quase inexistente. Deste modo, é a partir da ausência, da negação e da desapropriação que a relação do sujeito com o espaço de Montreal se constrói.

A exemplo do espaço, a relação do sujeito com o tempo (passado, presente) condiciona a relação de seu ser com o mundo enquanto mundo significante. Construir sua identidade é, no sentido cognitivo, construir a dimensão temporal de seu ser e de seu devir. Ora, em inúmeros romances migrantes, a apreensão do tempo está ligada a uma temporalidade anterior. Em outras palavras, existe um tempo antes da alteridade, que permite captar sua dimensão propriamente dramática. Pela própria natureza de sua condição de migrante, os personagens são frequentemente fixados em um passado do qual não conseguem se desprender.
Em A Casa dos Espelhos, o narrador, ao fechar os olhos a tudo que o rodeia, refugia-se no passado: "Mesmo que eu preste atenção ao presente, é sempre confundindo-o com as imagens do passado; a tal ponto que o novo acaba por perder interesse" (p. 21-22); ou ainda: "nunca revi o pátio, não é necessário. Ele está sempre comigo" (p. 196). É evidente que, nesse dispositivo espaço-temporal, nenhuma transformação cultural pode se efetuar. Esse sujeito, como muitos outros migrantes, é um sujeito à deriva: preso em suas origens, assombrado por seu passado e seu país natal, ao qual não pertence mais, permanece um melancólico, um sujeito desarraigado: "O desarraigado oscila assim entre dois tempos, o seu e o real, para frente e para trás, sem poder se fixar" (p. 360). Lúcido, o narrador compreende que construiu para si uma identidade de exilado. "Os exilados [...] são melancólicos, seu tempo é fechado e, quando falam de futuro, é para voltar a esse passado do qual nunca saíram" (362).

\section{O sujeito transnacional}

Embora se debruce sobre o sujeito pós-moderno e migrante, a crítica recente, em particular norte-americana, interroga-se também sobre o conceito de sujeito transnacional. Inspirado, entre outros, pelos trabalhos de Homi Bhabha e de Gayatra Spivak, o termo designa certos fenômenos de migrância. Como indica o prefixo trans, o transnacionalismo implica um processo segundo o qual formações identitárias tradicionalmente circunscritas por fronteiras políticas e geográficas ultrapassam fronteiras nacionais para produzir novas formações identitárias. Há um distanciamento do discurso identitário estrito em proveito da pulverização, da heterogeneidade e da movência. $O$ transnacionalismo recusa as definições identitárias estanques. Assim, para o crítico JeanJacques Thomas, uma obra transnacional transcende toda problemática ligada à questão do nacionalismo literário. Trata-se de uma nova maneira de se conceber, de se descrever, de ser humano.

O sujeito transnacional tem um certo parentesco com o sujeito migrante na medida em que também é um emigrante que escolheu ou foi forçado a deixar seu país natal. Porém, diferentemente do sujeito migrante (tal como descrevi), o transnacional rejeita a noção de uma identidade formada a partir dos critérios de raça ou de local de origem em proveito de uma identidade complexa, mutável, frequentemente multicultural e exterior ao recinto das lembranças. Amaryll Chanady mostra bem a problemática dessa concepção identitária, ao questionar a significação exata da categoria "ítalo-canadense" (ou ítalo-quebequense), considerando a imensa diversidade cultural e linguística do país. Pode-se realmente falar, ela pergunta, de uma só e única identidade ética que subsume 
tanto os imigrantes de Veneza quanto os de Nápoles? Por outro lado, o que dizer das distinções de classe, de educação, de cultura e de estilos de vida? Fazendo eco a essas declarações, Neil Bissoondath desconstrói a noção de uma identidade homogênea entre os naturais de Trinidad e Tobago, esclarecendo que seus amigos de infância eram de raças diferentes (brancos, negros, chineses, indianos, mulatos) e de religiões diversas (católicos, hindus, muçulmanos e protestantes). Não sem pesar, ele acrescenta que, no Canadá, eles são percebidos como um grupo homogêneo, sem diferenças culturais.

Na literatura quebequense, os textos de Ying Chen e de Joël Des Rosiers representam exemplos marcantes do transnacionalismo porque rejeitam os posicionamentos identitários de certos sujeitos migrantes. Vou examinar brevemente alguns aspectos de Quatre mille marches, de Yin Chen, para ilustrar os parâmetros de uma identidade transnacional.

Como se constrói a identidade transnacional de um sujeito? Ela implica, em primeiro lugar, uma nova relação com o espaço. Contrariamente aos sujeitos migrantes, que permanecem apegados a seu país natal, identificam-se e concebem-se em função desse país e sua cultura, o sujeito transnacional se define em função de um novo espaço: "Começo hoje a me apegar a outra paisagem, onde me sinto mais em casa, afirma Ying Chen. Meu verdadeiro país é onde eu me torno o que quero ser" $(2004$, p. 123). A aventura e a mudança de espaço subentendem a construção identitária: "eu me torno uma folha solitária que sonha em se replantar em outro lugar" (p. 42). Ora, um outro lugar hostil e pouco habitável para certos escritores migrantes é percebido e vivenciado como uma escolha que determina de maneira positiva a identidade do sujeito. Ying Chen não gosta, aliás, que os ocidentais vejam nela e em sua obra apenas estereótipos da cultura chinesa.

Diferentemente das narrativas migrantes, há nessa relação com o país natal uma rejeição à nostalgia: "Agora não sinto nenhum arrependimento por ter deixado Xangai. Minha vida anterior se torna um sonho evanescente" (p. 32). Do mesmo modo, Joël Des Rosiers afirma: "eu sou um homem livre de todas as tradições" (1996, p. 13). Estamos bem longe, nessas constatações, dos entrelugares, dos no man's land descritos em inúmeros textos migrantes. Mais longe ainda de uma escrita da perda e da expropriação.

Quanto ao movimento e ao deslocamento, Ying Chen e Joël Des Rosiers os concebem de maneira semelhante. Percebendo-se como uma viajante, Chen fala da felicidade e da alegria da errância, conceito que parece perder toda sua conotação negativa. Um movimento de sobredeterminação começa, consequentemente, a se manifestar na construção identitária do sujeito: a relação com o espaço é um "aqui e agora" e de "presença no mundo", presença confirmada pela rejeição à nostalgia e pela alegria manifesta da viagem. Mas permanece, ainda assim, a questão da origem e da raça. Como isso se dá para Ying Chen? Ela recusa de maneira bastante brutal os estereótipos e o nacionalismo estrito:

Você tem certeza de que não sou cidadã de lugar nenhum [...]. Muitos ocidentais concordarão com você. Ficarão felizes em descobrir em mim manias chinesas [...] para me lembrar minha origem [...] minha lamentável condição de exilada, de dissidente, de estrangeira. (p. 57)

Joël Des Rosiers, poeta quebequense de origem haitiana, afirma que seus poemas, sobretudo em Tribu, exprimem o desejo e o prazer de se descentrar, de se "desarraigar" em uma era de "destribalização", em que ultrapassar as fronteiras de raça, de classe, de língua passa a ser uma necessidade vital. Contra a imutabilidade dos lugares que formam guetos identitários, a multiplicidade dos lugares e os movimentos migratórios convidam à descoberta do Outro e do alhures para que o eu "siga o ritmo da História":

A residência em um espaço dado, morar em um lugar, foi por muito tempo um critério de identidade. Ora, nessa era de migrações planetárias, de êxodos e de viagens, a atribuição identitária pelo local de origem ou de "transplantação", ou ambos ao mesmo tempo, passa a ser inoperante (p. XVII).

Certos críticos percebem o transnacionalismo como sendo utópico ou suspeito na medida em que ele encoraja uma denegação dos critérios de raça, de nacionalidade e de cultura. Outros críticos ressaltam que esse fenômeno destoa dos movimentos políticos que abalam o mundo atualmente. Seja como for, uma coisa é certa: a literatura atual revela uma grande variedade de construções identitárias - pós-modernas, migrantes, transnacionais; pós-modernas e migrantes; pós-modernas e transnacionais. Desconstruindo as grandes metanarrativas, valorizando a diversidade e a heterogeneidade, o pós-modernismo traçou efetivamente o caminho para as escrituras migrantes e pós-modernas. Em contrapartida, essa nova literatura amplia, devido à sua natureza excêntrica, o alcance epistemológico e sociocultural do pós-modernismo. Fragmentado e móvel, o sujeito contemporâneo se escreve e se inscreve então em um vasto espaço literário em vias de mudança e de transformação.

\section{Referências}

AGNANT, Marie-Célie. La Dot de Sara. Montréal: Remueménage, 2002. 
AQUIN, Hubert. Trou de mémoire. Québec: BQ, 1993.

BHABHA, Homi. The Location of Culture. London/New York: Routledge, 1994.

BISSOONDATH, Neil. Selling Illusions: The Cult of Multiculturalism in Canada. Harmondsworth: Penguin, 1994.

CHANADY, Amaryll. The Construction of Minority Subjectivities at the End of the Twentieth Century. Adjacencies: Minority Writing in Canada. BENEVENTI, Domenic A.; CANTON, Licia; MOYES, Lianne (Coord.). Toronto: Guernica, 2004. p. 21-38.

CHEN, Ying. Quatre mille marches. Montréal: Boréal, 2004.

DES ROSIERS, Joël. Théories Caraïbes: Poétique $d u$ déracinement. Montréal: Triptyque, 1996.

FARHOUD, Abla. Le Bonheur a la queue glissante. Montréal: Hexagone, 1998.

KOKIS, Sergio. Le Pavillon des miroirs. Montréal: XYZ, 1995.

LANDOWSKI, Éric. Présences de l'autre: essais de sociosémiotique II, Paris: Presses universitaires de France, 1997.

LYOTARD, Jean-François. La Condition postmoderne. Paris: Minuit, 1979.
MICONE, Marco. Le Figuier enchanté. 1992. Montréal: Boréal, 1998.

PATERSON, Janet M. Moments postmodernes dans le roman québécois. Ottawa: Presses de l’Université d'Ottawa, 1993.

PATERSON, Janet M. Figures de l'Autre dans le roman québécois. Québec: Nota bene, 2004.

ROBIN, Régine. La Québécoite. Montréal: Typo, 1993.

SPIVAK, Gayatri. In Other Worlds. New York: Routledge, 1987.

TAYLOR, Charles. Sources of the Self: The Making of the Modern Identity. Cambridge: Cambridge UP, 1989.

THOMAS, Jean-Jacques. La Poétique historique transnationale de Joël Des Rosiers. Québec Studies, v. 37, p. 79-89, 2004.

VILLEMAIRE, Yolande. La Vie en prose. Montréal: Les Herbes rouges, 1980

Recebido: 29 de outubro de 2014

Aprovado: 14 de dezembro de 2014

Contato: principal.innis@utoronto.ca 